\title{
New Non-Invasive Index for Detecting Esophageal Varices in Patients with Liver Cirrhosis
}

\author{
Mona A. Amin'1, Ahmed E. El-Badry', May M. Fawzi'1, Dalia A. Muhammed², Shorouk M. Moussa ${ }^{1}$ \\ ${ }^{1}$ Internal Medicine, Cairo University, Cairo, Egypt \\ ${ }^{2}$ Community Medicine, Cairo University, Cairo, Egypt \\ Email: monasleman@hotmail.com
}

How to cite this paper: Amin, M.A., ElBadry, A.E., Fawzi, M.M., Muhammed, D.A. and Moussa, S.M. (2016) New Non-Invasive Index for Detecting Esophageal Varices in Patients with Liver Cirrhosis. Open Journa of Internal Medicine, 6, 101-111. http://dx.doi.org/10.4236/ojim.2016.64016

Received: October 6, 2016

Accepted: November 11, 2016

Published: November 14, 2016

Copyright $\odot 2016$ by authors and Scientific Research Publishing Inc. This work is licensed under the Creative Commons Attribution International License (CC BY 4.0).

http://creativecommons.org/licenses/by/4.0/ (c) (i) Open Access

\section{Abstract}

Introduction: Many studies have shown that clinical, biochemical and ultrasonographic parameter are predictive of the presence and grading of esophageal varices. Aim of Study: Validation of a noninvasive test called P2/MS and its comparison with other noninvasive tests for the detection of high risk esophageal varices. Patients and Methods: We prospectively enrolled 125 consecutive patients with liver cirrhosis. Complete blood count [CBC], Platelet count by direct method, Liver functions [serum bilirubin, AST, ALT, prothrombin time and concentration and serum albumin], kidney functions, hepatitis markers for B \& C, abdominal ultrasonography and upper gastrointestinal endoscopy were done for each patient. Calculation of P2/MS [Platelet count $)^{2} /$ \{monocyte fraction $(\%) \times$ segmented neutrophil fraction (\%)], API [age-platelet index], APRI [AST-to-platelet ratio index], SPRI [spleen-toplatelet ratio index], ASPRI [age-spleen-to-platelet ratio index] scores and correlating the different scores with the grade of esophageal varices found on upper endoscopy. Results: During processing of our patient's data, we found certain relation between segmented neutrophils, monocytes, platelet count, total bilirubin and the degree of esophageal varices for the detection of high risk varices and a new equation was formulated and we called it P2/MS-B. In predicting high risk esophageal varices HREV, the area under the curve for this new variable was $[0.909,95 \%$ confidence interval 0.858 $0.961, \mathrm{p}=0.000$ ] which was significantly higher than all the other variables including P2/MS for the detection of HREV. The sensitivity of the new equation for the detection of HREV is $85.3 \%$, the specificity is $83.1 \%$, the positive predictive value is $87.9 \%$, the negative predicative value is $86.0 \%$ and the overall accuracy of the test is $85.6 \%$. Conclusion: A newly detected noninvasive variable for detecting HREV may reliably screen liver cirrhosis patients for HREV and avoid unnecessary endoscopy in low risk patients.

\section{Keywords}

Esophageal Varices, Noninvasive Indices 


\section{Introduction}

Portal hypertension is a progressive complication of liver cirrhosis and it is the cause of high morbidity and mortality. Gastroesophageal varices are present in approximately $50 \%$ of patients with cirrhosis. The management of cirrhotic patients with varices differs according to the grade of varices or the presence of acute variceal bleeding. While varices are found in $40 \%$ of Child A patients, they can be present in up to $85 \%$ of Child C patients [1]. Cirrhotic patients develop varices at a rate of $8 \%$ per year and the strongest predictor for their development in those who have no varices at the time of initial endoscopic screening is a portal-hepatic venous pressure gradient (HVPG) more than $10 \mathrm{mmHg}$ [2] [3]. Variceal hemorrhage occurs at a yearly rate of $5 \%-15 \%$, and its most important predictor is the size of varices, with the highest risk of first hemorrhage occurring in patients with large varices [4].

The gold standard for the diagnosis of varices is esophagogastroduodenoscopy (EGD). It is recommended that patients with cirrhosis undergo endoscopic screening for varices at the time of diagnosis [5] [6]. Since the point prevalence of medium/large varices is approximately $15 \%-25 \%$ [1], the majority of subjects undergoing screening EGD either do not have varices or have varices that do not require prophylactic therapy. Thus, several models have been proposed to predict the presence of high risk varices by nonendoscopic methods and have excited considerable interest among researchers. Multiple studies have evaluated possible noninvasive markers of esophageal varices in patients with cirrhosis such as: the platelet count, Fibrotest, spleen size, portal vein diameter, and transient elastography [7] [8]. Lee and coworkers recently proposed a simple noninvasive test, P2/MS, which they developed in a study of patients with virusrelated chronic liver disease (CLD) [9]. They used the following formula: (platelet count $)^{2} /[$ monocyte fraction (\%) - segmented neutrophil fraction (\%)]. However, P2/MS has received little external validation of its diagnostic accuracy and cut-off values for detection of esophageal varices [10]. We, therefore, conducted the current study to externally validate P2/MS, to determine optimal thresholds to predict high risk esophageal varices (HREV) in patients with liver cirrhosis, and to compare results of the $\mathrm{P} 2 / \mathrm{MS}$ index with those from other noninvasive tests.

\section{Patients and Methods}

\subsection{Patients}

Between August 2010 and May 2011, we prospectively enrolled 125 consecutive patients with liver cirrhosis presenting for routine follow up of their condition at Internal Medicine Department Kasr El-Aini Hospital. Cirrhosis was diagnosed clinically by history and physical examination, as well as by standard laboratory and sonographic data. The exclusion criteria included the following: the presence of infection or fever; alcohol ingestion in excess of $30 \mathrm{~g} /$ day for more than 45 years; previous variceal bleeding; beta-blocker therapy; previous endoscopic treatments (bandligation or sclerotherapy); previous surgery forportal hypertension or Transjugular Intrahepatic Portosystemics- 
tent shunt placement; portal vein orsplenic vein thrombosis and Hepatocellular Carcinoma. All subjects received complete biochemical evaluations, ultrasonography and endoscopy within 2 days of admission. The study protocol followed the ethical guidelines of the 1975 Declaration of Helsinki. We obtained written, informed consent from each participant or a responsible family member after fully explaining the possible complications of the diagnostic procedures. The Institutional ethical committee approved this study.

\subsection{P2/MS, and Other Noninvasive Tests}

For the calculation of noninvasive tests including P2/MS, the laboratory data obtained on the same day as the endoscopic examination were used. Within one day following or preceding the endoscopy, all patients underwent an ultrasonographic examination of the upper abdomen, performed by an experienced operator blinded to the patients' clinical and laboratory data. A spleen bipolar diameter was defined as the greatest longitudinal dimension at the level of splenic hilum on the image monitor using electronic calipers [11].

The values for P2/MS and other noninvasive tests were calculated automatically, using previously published data (Table 1) [12] [13] [14] [15].

\subsection{Endoscopic Evaluation}

An experienced gastroenterologist blinded to the patients' clinical and laboratory data confirmed all endoscopic findings. Esophageal varices were classified as: small [veins minimally elevated above the esophageal mucosal surface], medium [tortuous veins occupying less than one third of the esophageal lumen], or large [those occupying more than one-third of the esophageal lumen]. In this study, patients with high risk esopha-

Table 1. Simple fibrosis tests composed of clinical and laboratory parameters.

\begin{tabular}{|c|c|}
\hline Fibrosis test & Calculation \\
\hline $\mathrm{P} 2 / \mathrm{MS}$ & {$[\text { Platelet count }(109 / \mathrm{L})]^{2} /[$ monocyte fraction (\%)_segmented neutrophil fraction (\%)] } \\
\hline AAR & AST/ALT \\
\hline API & $\begin{array}{l}\text { Age (years): }<30=0 ; 30-39=1 ; 40-49=2 ; 50-59=3 ; 60-69=4 ; \geq 70=5 \\
\text { Platelet count }(109 / \mathrm{L}): \geq 225=0 ; 200-224=1 ; 175-199=2 ; 150-174=3 ; \\
125-149=4 ;<125=5 \mathrm{AP} \text { index is the sum of the above (possible value } 0-10)\end{array}$ \\
\hline APRI & {$\left[(\right.$ AST/ULN)/platelet count $(109 / \mathrm{L})] \_100$} \\
\hline SPRI & Spleen size $(\mathrm{cm}) /$ platelet count $(109 / \mathrm{L}) \_100$ \\
\hline ASPRI & $\begin{array}{c}\text { Age (years): }<30=0 ; 30-39=1 ; 40-49=2 ; 50-59=3 ; 60-69=4 ; \geq 70=5 \\
\text { ASPRI is the sum of age and SPRI }\end{array}$ \\
\hline $\begin{array}{l}\text { Formula by } \\
\text { Berzigotti et al. (16) }\end{array}$ & Risk score $=[-0.193+(-0.359 \times$ albumin $)+(16.456 \times$ INR $)+(-0.016 \times$ ALT $)]$ \\
\hline $\begin{array}{l}\text { Our discovered } \\
\text { formula }\end{array}$ & $\begin{array}{c}\text { Final equation }=\mathrm{e}^{*} / 1+\mathrm{e}^{*} \\
\text { Where }^{*}=-5.192+(0.086 \times \text { segmented neutrophils })+(0.381 \times \text { monocytes })- \\
(0.04 \times \text { platelet })+(0.637 \times \mathrm{T} . \text { bilirubin }) \\
\text { And } \mathrm{e}=\text { exponential }\end{array}$ \\
\hline
\end{tabular}


geal varices (HREV) were defined as those with medium or large esophageal varices and those with small varices but with red signs [No. $=66$ patients] and represent $52.8 \%$ of all cases.

\subsection{Statistical Analysis}

The goals of this study were to validate the diagnostic value of P2/MS for the detection of esophageal varices and to estimate optimal P2/MS cut-off points to indicate when a patient with liver cirrhosis should undergo prophylactic treatment. To assess the diagnostic accuracy of each noninvasive index, receiver operating characteristic [ROC] curves were constructed and the corresponding areas under the ROC curve [AUROC] were computed. The data was coded and entered using the statistical package SPSS version 15. The data was summarized using descriptive statistics: median and range, minimal and maximum values for quantitative variables and number and percentage for qualitative values. Statistical differences between groups were tested using Chi Square test for qualitative variables, independent sample $[\mathrm{T}]$ test for quantitative normally distributed variables while Nonparametric Mann Whitney test was used for quantitative variables which aren't normally distributed. Correlations were done to test for linear relations between variables. Logistic regression analysis was done to test for significant predictors of outcome variable.ROC curve was used to test the validity of different scores in diagnosing high risk esophageal varices. P-values less than or equal to 0.05 were considered statistically significant.Sensitivity, Specificity, positive predictive value PPV and negative predictive value NPV of different tests were calculated.

\section{Results}

\subsection{Patient Characteristics}

The mean age of the patients [ 86 males, 39 females] was $55.17 \pm 7.73$ years (Table 2). Of these 125 patients, 115 [92\%] had esophageal varices [61 classified as small, 36 as medium and 18 as large] and 66 had high risk esophageal varices [52.8\%]. The median platelet count was $100\left[10^{9}\right] / \mathrm{L}$ [interquartile (IQR) 20 - 440], the median segmented neutrophil fraction 65\% [IQR 42 - 89] and the median monocyte fraction $8 \%$ [IQR 1 $15]$.

\subsection{Comparisons of the P2/MS Index and Our New Index with Other Noninvasive Tests}

P2MS was calculated [mean 67.67, median 20.74 (IQR 3.00 - 849.06)]. The patients without esophageal varices [median 46.94, IQR 9.04 - 849.06] had a higher P2/MS value than those with esophageal varices [median 12.48, IQR (3.00 - 107.53), $\mathrm{P}=0.000$ ], suggesting that the higher the score, the lower the likelihood of esophageal varices. In predicting high risk esophageal varices, area under the curve for P2/MS was [0.897, 95\% confidence interval (CI) 0.841 - 0.953] which showed values better than those of AAR [0.511, 95\% CI 0.405-0.618; $\mathrm{P}=0.828$ ], API [0.757, 95\% CI $0.669-0.845 ; \mathrm{P}=0.000]$, SPRI [0.767, 95\% CI $0.684-0.850 ; \mathrm{P}=0.000$ ], ASPRI [0.771, 95\% CI $0.688-0.853 ; \mathrm{P}=$ 
Table 2. Main clinical characteristics and laboratory results of the patients.

\begin{tabular}{|c|c|c|c|}
\hline Variables & Median & Minimum & Maximum \\
\hline Age years & 55 & 33 & 70 \\
\hline Gender $(M / F)$ & & $86 / 39$ & \\
\hline Body mass index $\left(\mathrm{kg} / \mathrm{m}^{2}\right)$ & 23 & 18 & 28 \\
\hline Child-Pugh (A/B/C) & & $1 / 74 / 50$ & \\
\hline White cell count $(/ \mu \mathrm{l})$ & 5400 & 1700 & 9800 \\
\hline Segmented neutrophil fraction (\%) & 65 & 42 & 89 \\
\hline Monocyte fraction (\%) & 8 & 1 & 15 \\
\hline Haemoglobin (g/dl) & 10 & 7 & 12 \\
\hline Platelet count $\left(10^{9} / \mathrm{L}\right)$ & 100 & 20 & 440 \\
\hline Prothrombin time (INR) & 1.50 & 1.06 & 2.60 \\
\hline Total bilirubin (mg/dl) & 1.30 & 0.10 & 5 \\
\hline Albumin (g/dl) & 2.50 & 1.40 & 3.30 \\
\hline AST (IU/L) & 57 & 16 & 200 \\
\hline ALT (IU/L) & 38 & 8 & 170 \\
\hline BUN (mg/dl) & 10 & 3 & 18 \\
\hline Creatinine (mg/dl) & 0.90 & 0.40 & 1.20 \\
\hline Spleen diameter $(\mathrm{cm})$ & 15 & 9.50 & 26.60 \\
\hline Varices present (yes/no) & & $115 / 10$ & \\
\hline esophageal varices size $(1 / 2 / 3)$ & & $61 / 36 / 18$ & \\
\hline High-risk esophageal varices (yes/no) & & $66 / 59$ & \\
\hline Portal hypertensive gastropathy (yes/no) & & $70 / 55$ & \\
\hline
\end{tabular}

AST: aspartate aminotransferase, ALT: alanine aminotransferase, BUN: blood urea nitrogen.

$0.000]$ and APRI [0.697, 95\% CI $0.605-0.788 ; \mathrm{P}=0.000$ ] and the formula by Berzigotti et al. [16] were 0.573 [ $95 \%$ CI $0.471-0.675$ ], all of which were significantly lower than that of P2/MS (Table 3).

During processing of our patients' data and on doing bivariate analysis, we found a certain relation between segmented neutrophil, monocytes, platelet count and total bilirubin in detection of HREV, so we entered those variables in a logistic regression model and found data depicted in Table 4 from which we obtained a new formula for predicting HREV. We named this formula P2/MS-B. Accordingly, a probability score was calculated for each patient, and then we analyzed this score to the ROC curve to validate it. In predicting high risk esophageal varices, area under the curve for this new variable was $[0.909,95 \%$ confidence interval $(\mathrm{CI}) 0.858-0.961, \mathrm{P}=0.000]$. This means it showed better values than all other variables including P2/MS.

\subsection{Determination of the Optimal Cut-Off Values}

As the central goal of this study, we sought to validate the noninvasive P2/MS test as a 
Table 3. Correlation of the noninvasive scores and the degree of esophageal varices.

\begin{tabular}{cccc}
\hline & \multicolumn{2}{c}{ High risk esophageal varices } & Yes \\
\cline { 2 - 3 } Number & No & 66 & P value \\
\cline { 2 - 4 } Spleen diameter $(\mathrm{cm})$ & 59 & $15.95(9.5-26.6)$ & 0.080 \\
P2MS & $14.80(10-21.7)$ & $12.48(3-107.53)$ & 0.000 \\
AAR & $46.94(9.04-849.06)$ & $1.61(0.64-3.46)$ & 0.828 \\
API & $1.39(0.54-5.38)$ & $8(3-10)$ & 0.000 \\
SPRI & $7(2-10)$ & $18.79(5.83-80)$ & 0.000 \\
ASPRI & $11.55(3-46.44)$ & $22.11(7.83-83)$ & 0.000 \\
Berzigotti & $14.67(6.67-50.44)$ & $24.23(16.48-41.77)$ & 0.178 \\
APRI & $23.25(16.40-38.28)$ & $1.98(0.40-10.26)$ & 0.000 \\
\hline
\end{tabular}

Details of abbreviations above are outlined in Table 1.

Table 4. Analysis of the variables of the new equation.

\begin{tabular}{|c|c|c|c|c|c|c|}
\hline & $B$ & S.E & P-Value & $E X P[B]$ & \multicolumn{2}{|c|}{$95.0 \%$ C.I for $E X P[B]$} \\
\hline Segmented neutrophils & 0.086 & 0.029 & 0.003 & 1.089 & 1.030 & 1.152 \\
\hline Monocytes & 0.381 & 0.085 & 0.000 & 1.463 & 1.238 & 1.729 \\
\hline Platelet count $10^{9} / L$ & -0.040 & 0.009 & 0.000 & 0.961 & 0.943 & 0.979 \\
\hline Constant & -5.192 & 2.099 & 0.013 & 0.006 & & \\
\hline
\end{tabular}

predictor of HREV and use it to determine which patients should undergo prophylactic treatment.

At a P2/MS cut-off value of 28.84 the test achieved a PPV of $79.7 \%$, sensitivity $89.4 \%$, specificity $74.6 \%$, NPV $86.3 \%$ and total accuracy of $82.4 \%$. Thus, P2/MS reliably predicted HREV if the result was equal to or less than 28.84 with high accuracy. Above this number, HREV may be excluded with high accuracy and low-risk patients may avoid endoscopy (Table 5, Figure $1 \&$ Figure 2).

The cut off points for the other variables showed lower sensitivity and specificity compared to P2/MS or the new test variable P2/MS-B. Compared to other cut off values, the new variable was the only test that showed better accuracy in detecting HREV. At a cut-off value of 0.5743 , high risk esophageal varices were found when the numbers were greater than or equal to this number. The new test achieved a PPV of $87.9 \%$, a sensitivity of $85.3 \%$, a specificity of $83.1 \%$, a NPV of $86.0 \%$ and a total accuracy of $85.6 \%$.

\section{Discussion}

Current guidelines recommend periodic endoscopic screening to all cirrhotic patients 
Table 5. Suggested cut-off values all test variables for prediction of high risk esophageal varices.

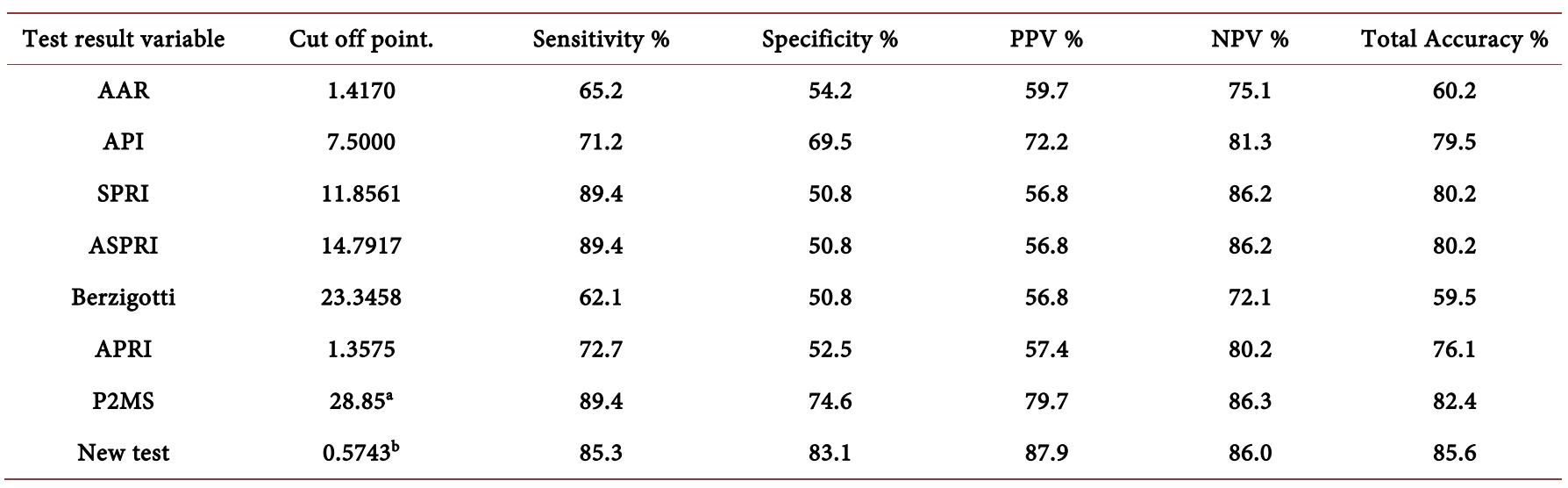

${ }^{a} \mathrm{High}$ risk esophageal varices positive if the result is less than or equal to this number. bHigh risk esophageal varices positive if the result is greater than or equal to this number.

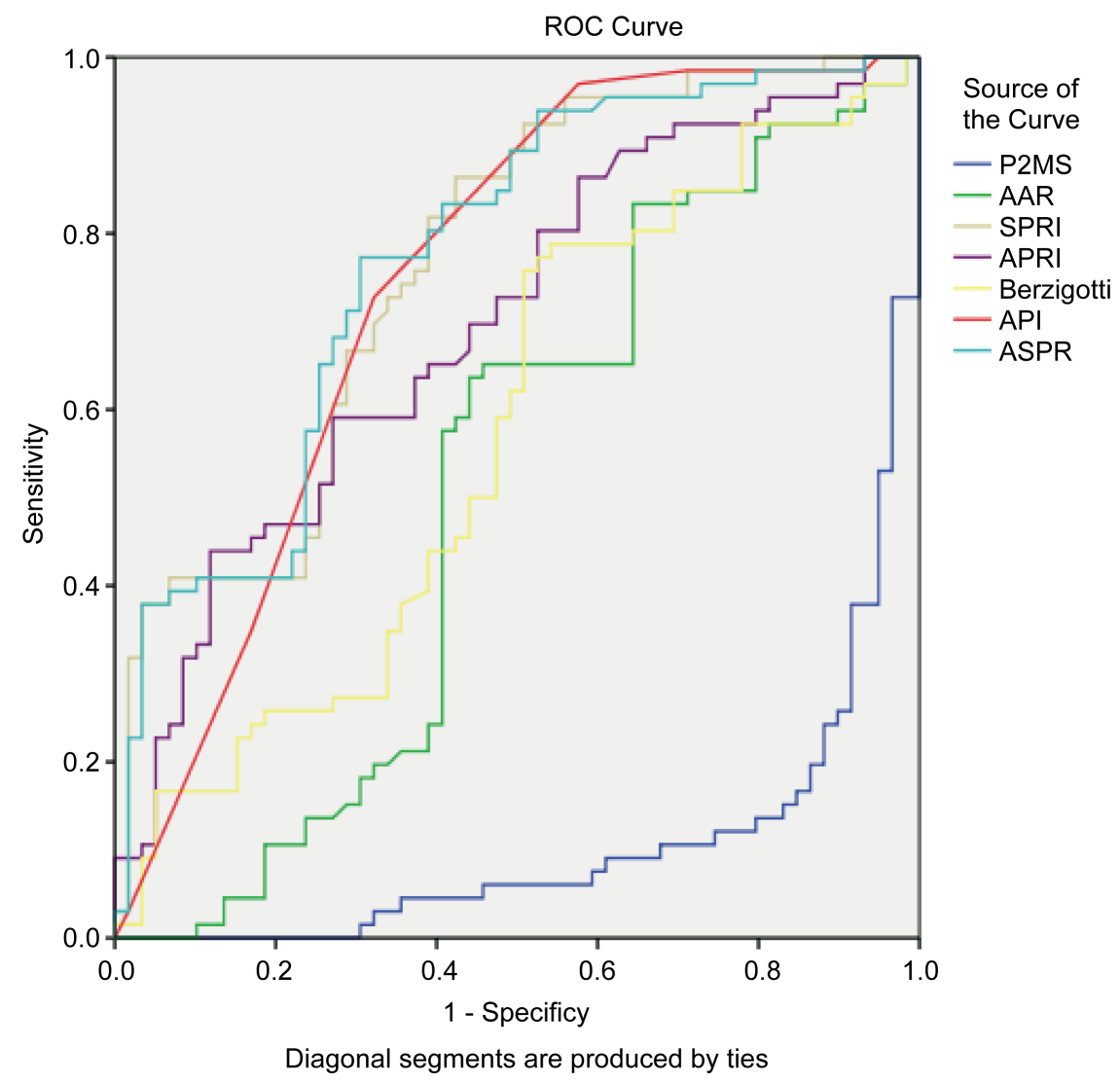

Figure 1. ROC curve of various test variables.

and prophylactic treatment for patients with HREV. But universal screening will lead to many unnecessary endoscopies [17]. Thus, various noninvasive tests based on biochemical and imaging studies have been proposed [12] [13] [14] [15]. This is particularly important in nations whose healthcare budget is low and the availability of endoscopic units is limited. Indeed, selective screening endoscopy becomes cost-effective 


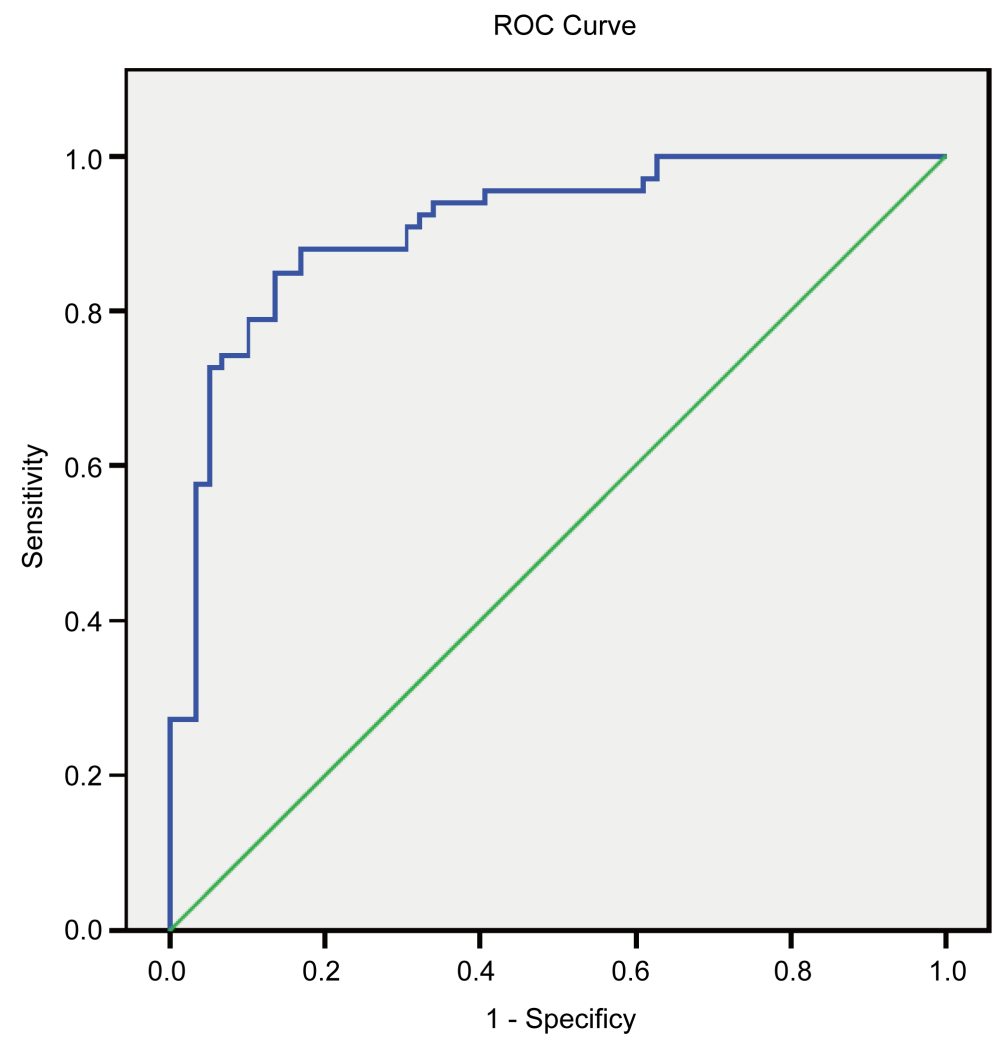

Figure 2. ROC curve of our new test variable.

with respect to universal screening endoscopy when non-invasive tests are sufficiently reliable to rule-in or rule-out the presence of esophageal varices.

A new index, P2/MS, based on a complete blood count, is specifically designed to predict esophageal varices in chronic liver disease. We conducted validation of the P2/MS index, and can now suggest optimal cut-off points to predict the presence of HREVs in patients with liver cirrhosis. Our study, has shown that a combination of simple, non-invasive serum markers could avoid performing unnecessary endoscopies, with only a small number of misdiagnosed cases.

In terms of the AUROC, P2/MS showed a high likelihood of reliably identifying patients with HREV [0.897], with values slightly lower than those seen in the other study by Beom Kyung et al. [0.941] [18]. In predicting HREV, P2/MS showed a higher accuracy than all variables except for our new test variable. We have suggested one cut off point for detection of HREV, which differ slightly from those of Beom Kyung et al. who used two cut off values so patients may be in the zone between the two cut off values. Above a cut-off value for P2/MS of 28.85, HREV could be excluded, with a negative predictive value [NPV] of $86.3 \%$. Based on this value, patients could avoid unnecessary endoscopy. These patients have a low risk of bleeding and periodic follow up using this formula could be considered adequate. In contrast to other studies, our study aimed primarily to predict the presence of HREV rather than varices of any size, with the aim of selecting these patients for prophylactic endoscopic ligation. Empirical Beta blocker 
therapy for primary prophylaxis can no longer be recommended for all cirrhotic patients without diagnostic endoscopy; it was not found to incur long term benefit. The formula P2/MS has several clinical advantages. First of all, one can easily calculate P2/MS at the bedside or in the outpatient clinic, as it does not require standardization and is free of intra-/interobserver variability. This make it different from other noninvasive tests that use ultrasonographic parameters such as portal vein velocity, portal vein diameter, hepatic impedance indexes, splenic impedance indexes and splenic diameter [19] [20]. We were able to detect a new test variable for detection of HREV that shows better results than P2/MS [AUROC $=0.909$ ]. The sensitivity of the new equation for the detection of high risk esophageal varices is $85.3 \%$, the specificity is $83.1 \%$, the positive predictive value is $87.9 \%$ the negative predicative value is $86.0 \%$ and the overall accuracy of the test is $85.6 \%$ compared to P2/MS test which has a sensitivity of $89.4 \%$ a specificity of $74.6 \%$, a positive predictive value of $79.7 \%$, a negative predicative value of $86.3 \%$ and an overall accuracy of $82.4 \%$. This new formula is a preliminary effort; its strength lies in the incorporation of a parameter that is affected by the degree of cirrhosis but it requires further assessment and validation over a large scale of patients.

\section{Conclusion}

P2/MS as well as P2/MS-B formulae are reliable means for detecting HREV. They are noninvasive, exhibit a high rate of accuracy and are cost effective.

\section{Recommendation}

Due to the small numbers of patients included in our study, reassessment of our new variable on a larger number of patients before validation is recommended.

\section{Conflict of Interest}

No conflict of interest of any of the authors.

\section{Consent}

The study protocol followed the ethical guidelines of the 1975 Declaration of Helsinki. We obtained written, informed consent from each participant or a responsible family member after fully explaining the possible complications of the diagnostic procedures.

\section{References}

[1] Pagliaro, L., D’Amico, G., Pasta, L., Politi, F., Vizzini, G., Traina, M., et al. (1994) Portal Hypertension in Cirrhosis: Natural History. In: Bosch, J. and Groszmann, R.J., Eds., Portal Hypertension. Pathophysiology and Treatment, Blackwell Scientific, Oxford, 72-92.

[2] Groszmann, R.J., Garcia-Tsao, G., Bosch, J., Grace, N.D., Burroughs, A.K., Planas, R., et al., The Portal Hypertension Collaborative Group (2005) Betablockers to Prevent Gastroesophageal Varices in Patients with Cirrhosis. New England Journal of Medicine, 353, 22542261. http://dx.doi.org/10.1056/NEJMoa044456

[3] Merli, M., Nicolini, G., Angeloni, S., Rinaldi, V., De Santis, A., Merkel, C., et al. (2003) In- 
cidence and Natural History of Small Esophageal Varices in Cirrhotic Patients. Journal of Hepatology, 38, 266-272. http://dx.doi.org/10.1016/S0168-8278(02)00420-8

[4] The North Italian Endoscopic Club for the Study and Treatment of Esophageal Varices (1988) Prediction of the First Variceal Hemorrhage in Patients with Cirrhosis of the Liver and Esophageal Varices. A Prospective Multicenter Study. New England Journal of Medicine, 319, 983-989. http://dx.doi.org/10.1056/NEJM198810133191505

[5] Grace, N.D., Groszmann, R.J., Garcia-Tsao, G., Burroughs, A.K., Pagliaro, L., Makuch, R.W., et al. (1998) Portal Hypertension and Variceal Bleeding: An AASLD Single Topic Symposium. Hepatology, 28, 868-880. http://dx.doi.org/10.1002/hep.510280339

[6] D’Amico, G., Garcia-Tsao, G., Cales, P., Escorsell, A., Nevens, F., Cestari, R., et al. (2001) Diagnosis of Portal Hypertension: How and When. In: de Franchis, R., Ed., Portal Hypertension III. Proceedings of the Third Baveno International Consensus Workshop on Definitions, Methodology and Therapeutic Strategies, Blackwell Science, Oxford, 36-64.

[7] D’Amico, G. and Morabito, A. (2004) Noninvasive Markers of Esophageal Varices: Another Round, Not the Last. Hepatology, 39, 30-34. http://dx.doi.org/10.1002/hep.20018

[8] Garcia-Tsao, G., D’Amico, G., Abraldes, J.G., Schepis, F., Merli, M., Kim, W.R., et al. (2006) Predictive Models in Portal Hypertension. In: de Franchis, R., Ed., Portal Hypertension IV. Proceedings of the Fourth Baveno International Consensus Workshop on Methodology of Diagnosis and Treatment, Blackwell, Oxford, 47-100.

[9] Lee, J.H., Yoon, J.H., Lee, C.H., et al. (2009) Complete Blood Count Reflects the Degree of Oesophageal Varices and Liver Fibrosis in Virus-Related Chronic Liver Disease Patients. Journal of Viral Hepatitis, 16, 444-452. http://dx.doi.org/10.1111/j.1365-2893.2009.01091.x

[10] Kim, B.K., Han, K.H., Park, J.Y., et al. (2009) External Validation of P2/MS and Comparison with Other Simple Non-Invasive Indices for Predicting Liver Fibrosis in HBV-Infected Patients. Digestive Diseases and Sciences.

[11] Dittrich, M, Milde, S., Dinkel, E., Baumann, W. and Weitzel, D. (1983) Sonographic Biometry of Liver and Spleen Size in Childhood. Pediatric Radiology, 13, 206-211. http://dx.doi.org/10.1007/BF00973157

[12] Kim, B.K., Kim, S.A., Park, Y.N., et al. (2007) Noninvasive Models to Predict Liver Cirrhosis in Patients with Chronic Hepatitis B. Liver International, 27, 969-976. http://dx.doi.org/10.1111/j.1478-3231.2007.01519.x

[13] Sheth, S.G., Flamm, S.L., Gordon, F.D. and Chopra, S. (1998) AST/ALT Ratio Predicts Cirrhosis in Patients with Chronic Hepatitis C Virus Infection. American Journal of Gastroenterology, 93, 44-48. http://dx.doi.org/10.1111/j.1572-0241.1998.044_c.x

[14] Chan, H.L., Wong, G.L., Choi, P.C., et al. (2009) Alanine Aminotransferase-Based Algorithms of Liver Stiffness Measurement by Transient Elastography (Fibroscan) for Liver Fibrosis in Chronic Hepatitis B. Journal of Viral Hepatitis, 16, 36-44. http://dx.doi.org/10.1111/j.1365-2893.2008.01037.x

[15] Poynard, T. and Bedossa, P. (1997) Age and Platelet Count: A Simple Index for Predicting the Presence of Histological Lesions in Patients with Antibodies to Hepatitis C Virus. Journal of Viral Hepatitis, 4, 199-208. http://dx.doi.org/10.1046/j.1365-2893.1997.00141.x

[16] Berzigotti, A., Gilabert, R., Abraldes, J.G., et al. (2008) Noninvasive Prediction of Clinically Significant Portal Hypertension and Esophageal Varices in Patients with Compensated Liver Cirrhosis. American Journal of Gastroenterology, 103, 1159-1167. http://dx.doi.org/10.1111/j.1572-0241.2008.01826.x

[17] Garcia-Tsao, G., Sanyal, A.J., Grace, N.D. and Carey, W. (2007) Prevention and Management of Gastroesophageal Varices and Variceal Hemorrhage in Cirrhosis. Hepatology, 46, 
922-938. http://dx.doi.org/10.1002/hep.21907

[18] Kim, B.K., Han, K.-H., Park, J.Y., HoonAhn, S., Kim, J.K., et al. (2010) Prospective Validation of P2/MS Noninvasive Index Using Complete Blood Counts for Detecting Oesophageal Varices in B-Viral Cirrhosis. Liver International, 30, 860-866.

http://dx.doi.org/10.1111/j.1478-3231.2010.02260.x

[19] Blackstone, E.H. (2001) Breaking down Barriers, Helpful Breakthrough Statistical Methods You Need to Understand Better. Journal of Thoracic and Cardiovascular Surgery, 122, 430439. http://dx.doi.org/10.1067/mtc.2001.117536

[20] Rockey, D.C. (2008) Noninvasive Assessment of Liver Fibrosis and Portal Hypertension with Transient Elastography. Gastroenterology, 134, 8-14.

http://dx.doi.org/10.1053/j.gastro.2007.11.053

Submit or recommend next manuscript to SCIRP and we will provide best service for you:

Accepting pre-submission inquiries through Email, Facebook, LinkedIn, Twitter, etc.

A wide selection of journals (inclusive of 9 subjects, more than 200 journals)

Providing 24-hour high-quality service

User-friendly online submission system

Fair and swift peer-review system

Efficient typesetting and proofreading procedure

Display of the result of downloads and visits, as well as the number of cited articles

Maximum dissemination of your research work

Submit your manuscript at: http://papersubmission.scirp.org/

Or contact ojim@scirp.org 